\title{
Project Cost Overrun Management in Universities Using Partial Least Squares-Structural Equation Modelling
}

\author{
Abam Ayeni Omini ${ }^{1}$, Ogbonna Eric Nnamdi ${ }^{2}$, Nsien Edwin ${ }^{3}$, Nzeako Gladys ${ }^{1}$ \\ ${ }^{1}$ Department of Mathematics, Faculty of Science, Federal University Lafia, Lafia, Nigeria \\ ${ }^{2}$ Department of Statistics, Faculty of Science, Abia State Polytechnic, Aba, Nigeria \\ ${ }^{3}$ Department of Statistics, Faculty of Science, University of Uyo, Uyo, Nigeria
}

Email address:

abamayeni@gmail.com (A. A. Omini)

\section{To cite this article:}

Abam Ayeni Omini, Ogbonna Eric Nnamdi, Nsien Edwin, Nzeako Gladys. Project Cost Overrun Management in Universities Using Partial Least Squares-Structural Equation Modelling. American Journal of Applied Mathematics. Vol. 5, No. 4, 2017, pp. 108-113. doi: 10.11648/j.ajam.20170504.12

Received: May 9, 2017; Accepted: June 2, 2017; Published: July 13, 2017

\begin{abstract}
The construction industry is a very important sector of the Nigerian economy. It contributes significantly to the Gross National Product. Cost overrun is an integral part of the construction industry. It generates in projects financial loss to both contractors and owners (clients). It is an important parameter for success of any project that results to serious sequences. Cost overrun is a chronic problem for tertiary institutions. This is because, it is common for projects not to be completed on time and within the initial project budget. The paper assess the management of project cost overrun, reasons for cost overrun and suggested solutions in selected Public Tertiary Institutions in Lafia Metropolis using Partial Least Squares-Structural Equation Modelling (PLS-SEM). The results show that contractor's site management related factors has 97.6\% effect on cost overrun, followed by non-human resource related factors with an effect of $94.4 \%$ on cost overrun. The least was information and communication technology related factors having $75.7 \%$ effect on cost overrun. The findings reveal that the PLS-SEM is a model that evaluates a data as a collective entity.
\end{abstract}

Keywords: Cost, Overrun, Management, Project, Site

\section{Introduction}

Cost overrun is also known as cost increase or cost escalation which involves unexpected cost incurred in excess of budgeted amount due to an under estimation of actual cost during budgeting. Cost overrun in projects generates a financial loss to both contractors and owners (clients). Cost, according to Shreenaath, Arunmozhi \& Sivagamasundari [16] is an important parameter for success of any project and suggests that cost performance results in serious sequences of projects abandonment. In the light of the above, Rosenfield [15] considers cost overrun as a universal problem which can be resolved by identifying the root cause(s). However, Choudhury \& Phatak [6] defined cost overrun as the difference between the original cost estimate of a project and the actual construction cost on the completion of the work or project.

According to Abam \& Nzeako [1], the construction industry is a very important sector of the Nigerian economy. It contributes significantly to its Gross National Product. The rapid growth in Nigeria's economy and population, particularly during the oil-boom years, required additional physical infrastructures to accommodate additional inputs to various components of the national product. Similarly, Tertiary institutions are of uttermost relevance to the educational sector in every country. These schools serve as one of the major sectors of economic growth and development of any country, therefore, adequate infrastructures are needed in place for high quality education. Unfortunately, construction projects in tertiary institutions are being faced with chronic problems like time overrun, low productivity, low quality and cost overrun.

The research carried out in Kenya by Kagiri [7] reveals that time and cost overrun in projects are influenced or caused by many factors. "The research further states that the factors that hinder successful completion of projects on time with the budget and its quality are: contractors' inabilities, 
improper project preparation, resource planning, interpretation of requirements, works definition, timeliness, Government bureaucracy and risk allocation as having been significant contributors to overrun and also on ranking" (Kagiri, [7]). The list was topped with Government bureaucracy while risk allocation was shown to have been least significant. The research of Love et al [11] further reveals that "new procurement systems gives cost and time overrun percentages to be $11 \%$ and ( 13 to 25 ) \% respectively with the causes of overruns attributed to inadequate project formulation, poor planning and implementation, lack of project management during execution, manipulation by project champions and natural calamities and environment within which the project lies". Furthermore, in order to avoid project cost overrun, there is a need to look at the cost overrun assessment as a decision support tool for the project managers, cost estimators for the construction projects before the bidding stage. Hence, this work is aimed at assessing the project cost overrun management in public tertiary institutions in Lafia Metropolis using the partial least squares-structural equation modelling.

\section{Aim and Objectives}

The aim of this work is to "evaluate the management of cost overrun of projects in selected Public Tertiary Institutions in Lafia Metropolis using Partial Least SquaresStructural Equation Model (PLS-SEM)". The objectives of the study are to:

(1) Assess the management of project cost overrun in selected Public Tertiary Institutions in Lafia Metropolis using Partial Least Squares-Structural Equation Modelling.

(2) Determine the reasons for cost overrun in Public Tertiary Institutions in Lafia.

(3) Proffer solutions to problems of cost overrun in Public Tertiary Institutions in Lafia.

\section{Statement of Problem}

Cost overrun is a chronic problem for tertiary institutions. This is because, it is common for projects not to be completed on time and within the initial project budget. It is worthy of note that there has been more cases of cost overrun than time overrun. This makes the problem of cost overrun to be of great significance. Cost overrun is one of the most important challenges facing the tertiary institutions today hence incomplete buildings littered allround the campuses, abandonment of projects by contractors at sites, half and non-payment of salaries to staff, unavailability of lecture rooms and administrative buildings for the smooth running of the tertiary institutions. Considering the dire need to solve cost overrun and management problems in Nigerian Institutions, it is therefore important to identify the factors that contribute to the cost overrun in schools in order to avoid if not reduce the problems to its barest minimal. The research work therefore, looks at the evaluation and assessment of cost overrun management and identifying the factors influencing cost overrun in the public tertiary institutions of Lafia Metropolis using PLS-SEM.

\section{Theoretical Framework and Conceptual Framework}

The theoretical framework of this work is based on the following theory: RATIONAL CHOICE THEORY. Rational Choice Theory is an economic principle that states that individuals always make prudent and logical decisions (Investopedia, [13]). The theory explains further that individuals choose an outcome that provides the maximum net benefit [maximum benefit minus cost (budget)] (Wikipedia, [14]). That is, it may lead to cost overrun as a result of materials scarcity, inflation or strike due to delay in project execution.

According to Angelo and Reina in 2002 as cited by Abam \& Nzeako [1], the problem of cost overrun is critical and needs studies more to alleviate this issue. The study by Azhar, Farooqui \& Ahmed [3] states that in spite of its proven importance it is uncommon for project completion within estimated cost. However, Kaliba, Muya \& Mumba [8] established that bad or inclement weather due to heavy rains and floods, scope changes, environmental protection and mitigation costs, schedule delay, strikes, technical challenges, inflation and local government pressures were the major causes of cost escalation in Zambia's road construction projects (Abam \& Nzeako, [1]). Koushki, AI-Rashid \& Kartam [9] studied causes of cost overruns and identified the three main causes as contractor-related problems, material - related problems and again, owners' financial constraints. Bubshait \& Al-Juwait [4] listed the following as factors that cause cost overrun on projects in Saudi Arabia; "effects of weather, number of projects going on at the same time, social and cultural impacts, project location, lack of productivity standards, level of competitors, supplier manipulation, economic stability, and inadequate production of raw materials by the country and absence of construction cost data". Lee [10] examined cost overrun problem in Korean social overhead capital projects and in his study of 161 completed projects the causes of cost overruns were found as changes in scope, delays during construction, unreasonable estimation and adjustment of project costs and no practical use of the earned value management system while Sriprasert [17] mentioned "that low quality materials causes higher construction cost than expected because of the loss of materials during construction and this results from lack of standards for materials and management system and lack of ability of management to prevent cost overruns or to control construction costs causes many project to fail in achieving effective cost performance". Ali et al. [2] through questionnaire survey in different projects found that the main factors that contribute to cost overruns include inaccurate/poor estimation of original cost, project cost underestimation, improper planning, poor project 
management, lack of experience, poor contract management, inflation of project costs, high cost of machineries, fluctuation in price of raw materials, unforeseen site conditions, insufficient fund, obsolete/unsuitable construction equipment' methods and Mistake in design.

\section{Method of Data Analysis}

The population of study consists of all the contractors working for the public tertiary institutions in Lafia Metropolis. These institutions include: Federal University Lafia, abbreviated as FULafia, Nasarawa State Polytechnic, Lafia and College of Agriculture, Lafia. The research design used for the study is the descriptive sample survey. The sample of 25 contractors of construction companies working for these tertiary institutions in Lafia Metropolis were sampled using a Simple Random Sampling (SRS) technique. The questionnaire, the main instrument for the study was administered to the contractors of the companies and the results were analyzed using Partial Least Squares-Structural Equation Modeling (PLS-SEM).

The questionnaire was designed to reflect the causes of project cost overrun in tertiary institutions in Lafia Metropolis. The researcher constructed and used a 25-item questionnaire. This was administered on the respondents to collect the needed information. The questionnaire was constructed in two sections. Section A derived items on the respondents personal demographic and general information like sex, age, status etc. Section B was developed to rate the causes of project cost overrun in tertiary institutions in Lafia Metropolis. The questionnaire was constructed using the formation of a five-point likert scale. The response option ranged from NR to ER. The scale values allocated were 5, 4, 3,2 and 1 respectively. Respondents were required to indicate with a tick $(\sqrt{ })$ the option that they agree with. The instrument validated the content and to construct its validity, each of the instruments was scrutinized by experts in Operations Research and Construction Management. Their suggestions were adhered to strictly thus leading to the modification of relevant items.

In order to analyze the data got, the researcher used the Partial Least Square Structural Equation Modeling (PLS-SEM).

\section{Structural Equation Model}

Structural Equation Model (SEM) is a statistical model that seeks to explain the relationships among multiple variables. The two types include: Variance-based PLS (VBPLS) and Covariance-based PLS (CBPLS). VBPLS advantage over CBPLS is that:

(1) It has the ability to accommodate constructs measured by a large numbers of variables (Haenlein and Kaplan's work of 2004 as cited in Abam \& Nzeako [1]);

(2) It allows for greater complexity within the model and can be used with non-parametric data;

(3) Sample size requirements are not as robust and dependent on power analysis for a determination of an appropriate sample size;

(4) It attempts to maximize variance explained in the latent variables through the relationship with the independent variables (Haenlein and Kaplan's work of 2004 as contained in Abam \& Nzeako [1]).

Partial Least Squares (PLS) Structural Equation Modeling was developed by Chin and Frye in 2001 reviewed in the work of Mitzi (Maritza) [12]. PLS-SEM also referred to as PLS path modeling is a type of model that shows the relationship between latent variables which are connected using direct arrows called the path relationship. According to Chin [5], the work reveals that SEM involves three primary components: (1) Indicators (often called manifest variables or observed measures/variables). Indicators are usually represented as squares. For questionnaire-based research, each indicator represents a particular question. (2) Latent variables (or construct, concept, factor). Latent variables are normally drawn as circles. Latent variables are used to represent phenomena that cannot be measured directly. (3) Path relationships (correlational, one-way paths, or two way paths). These relationships are defined using arrows. Chin [5] further reveals that structural equation model include two types of latent variables: Exogenous constructs: these are the constructs that does not have a predecessor. Endogenous constructs: these are the constructs that does have a predecessor.

\section{Assessment of PLS-SEM}

PLS-SEM is assessed using the coefficient of determination $\left(\mathrm{R}^{2}\right)$ of each of the latent constructs. Coefficient of determination $\left(\mathrm{R}^{2}\right)$ is used to describe the overall goodness of fit of an estimated model one or more independent variables. $R^{2}$ ranges from " 0 " and " 1 ".

If $R^{2}=1$, it implies that there exist a perfect fit, that is $\hat{Y_{i}}=$ $Y_{i}$.

If $R^{2}=0$, it implies that there is no relationship between the estimator and estimate, that is $\hat{Y}_{i} \neq Y_{i}$.

Similarly, if $R^{2}>0.5$, it implies that there is a good fit of the model to the given data and if $R^{2}<0.5$, it implies that there is no good fit of the model to the given data.

$$
\begin{gathered}
R^{2}=\frac{E S S}{T S S}=\frac{\sum\left(\hat{Y_{i}}-\bar{Y}\right)^{2}}{\sum\left(Y_{i}-\bar{Y}\right)^{2}} \\
\quad \text { or } R^{2}=1-\frac{R S S}{T S S} \\
=1-\frac{\sum\left(Y_{i}-\hat{Y}\right)^{2}}{\sum\left(Y_{i}-\bar{Y}\right)^{2}}
\end{gathered}
$$

Where $Y_{i}=$ Actual value, $\bar{Y}=$ The mean of actual value and $Y=$ The estimated value.

Alternatively, $R^{2}$ can be evaluate as square of coefficient of correlation. 


\section{Result and Discussion}

The analyses of data collected from contractors in Lafia Metropolis working for selected public tertiary institutions using the study questionnaire were analyzed and presented in the form of frequency and numerical values using Partial Least Square Structural Equation Modeling (PLS-SEM).

The questionnaires were distributed to 30 respondents out of which 27 were returned. Table 1 shows the rate of study of responses from respondents.

Table 1. Response rate of study.

\begin{tabular}{llll}
\hline S/N & Rate of Responses & Frequency & Percentage \\
\hline & Complete Response & 25 & 92.6 \\
& Incomplete Responses & 2 & 7.4 \\
Total & & 27 & 100 \\
\hline
\end{tabular}

The results are presented using SMART PLS 3-SEM as the figures and tables below.

Definition of Latent Variables and Indicators. The Latent Variables (represented by a circle) are: Contractor Site Management Related Factors (CSMRF); Project Management and Contract Administration Related Factors (PMCARF); Non -Human Resource Related Factors (NRRF); Information and Communication Related Factors (ICTRF); Human Resource (Work force) Related Factors (HRRF); Financial Management Related Factors (FMRF); Design and Documentation Related Factors (DDRF)

Indicators (represented by a square are): $C_{1}=$ Poor Site Management and Supervision; $C_{2}=$ Incomplete
Subcontractors; $C_{3=}$ Schedule Delay;

$C_{4}=$ Inadequate Planning and Scheduling; $C_{5}=$ Lack of Experience; $C_{6}=$ Inaccurate Time and Cost Estimates; $C_{7}=$ Mistakes during Construction; $C_{8}=$ Inadequate Monitoring and Control; $P_{1}=$ Poor Project Management; $P_{2}$ =Change in the Scope of the Project; $P_{3}=$ Delays in Decision Making; $P_{4}=$ Inaccurate Quantity to Take -Off; $N_{1}=$ Fluctuation in Price of Materials; $N_{2}=$ Shortage of Materials; $N_{3}=$ Late Delivery of Materials and Equipment; $N_{4}$ =Equipment Availability and Failure; $I_{1}=$ Lack of Coordination between Parties; $I_{2}=$ Slow Information Flow between Parties; $I_{3}=$ Lack of Communication between Parties; $H_{1}=$ Labor Productivity; $H_{2}=$ Shortage of Site Workers; $H_{3}=$ Shortage of Technical Personnel (Skilled Labor); $H_{4}=$ High Cost of Labor; $H_{4}=$ Labor Absenteeism; $F_{1}=$ Cash Flow and Financial Difficulties Faced by Contractors; $F_{2}=$ Poor Financial Control on Site; $F_{3}=$ Financial Difficulties Faced by Owners; $F_{4}=$ Delay in Progress Payment by Owner; $F_{5}=$ Delay in Payment to Suppliers/Subcontractors; $F_{6}=$ Contractual Claims Such as Extension of Time with Cost Claims; $D_{1}=$ Frequent Design Change; $D_{2}=$ Mistakes and Errors in Designs; $D_{3}=$ Incomplete Design at the Time of Tender; $D_{4}=$ Poor Design and Delays in Designs; $D_{5}=$ Delay in Preparation and Approval of Drawings.

Figure 1: Pictorial Representation of PLS-SEM using Smart PLS 3.

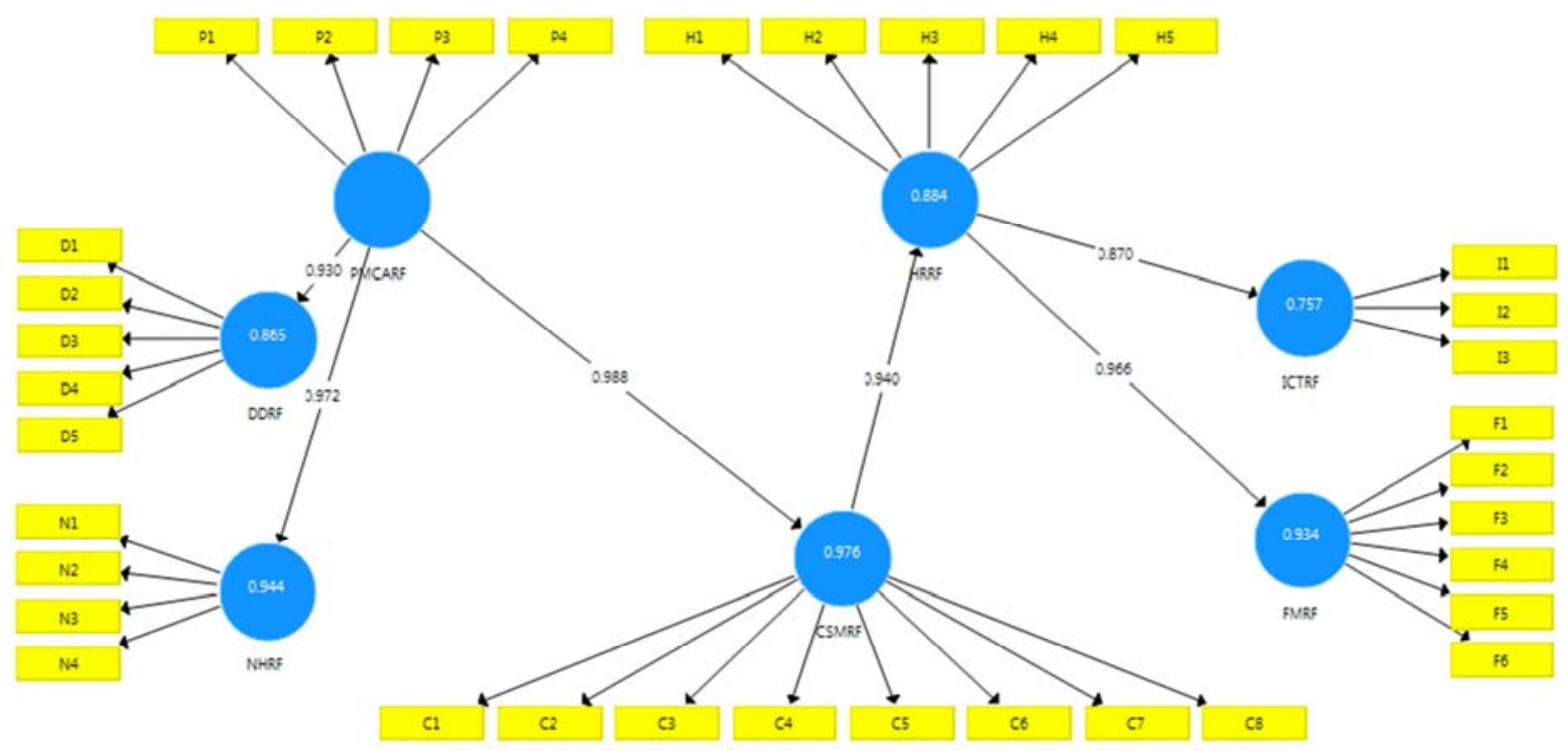

Figure 1. PLS-SEM.

Table 5. Inner Model.

\begin{tabular}{|c|c|c|c|c|c|c|c|}
\hline & CSMRF & DDRF & FMRF & HRRF & ICTRF & NHRF & PMCARF \\
\hline CSMRF & & & & 1 & & & \\
\hline DDRF & & & & & & & \\
\hline FMRF & & & & & & & \\
\hline HRRF & & & 1 & & 1 & & \\
\hline ICTRF & & & & & & & \\
\hline NHRF & & & & & & & \\
\hline PMCARF & 1 & 1 & & & & 1 & \\
\hline
\end{tabular}


The results represented in in Table 4 shows that the major causes of cost overrun in selected public tertiary institution in Lafia metropolis as analyzed using PLS-SEM are: the validity and reliability of each constructs as: Project management and contract administration related factors has the least coefficient in Cronbach alpha and Composite reliability of $92.0 \%$ and $94.5 \%$ respectively while non-human resources related factors has higher percentages both as $97.4 \%$ and $98.1 \%$ respectively. Furthermore, non-human resources related factors is the highest in both AVE and rho_A as $92.8 \%$ and $97.5 \%$ respectively and the least in both is contractor site management related factors of $71.6 \%$ and $94.9 \%$ respectively. Researchers believe that cronbach alpha is the most commonly used reliability coefficient because it seeks to generalize a measure of a uni-dimensional and multi-dimensional item scale's internal consistency (reliability). Table 2 shows that contractor site management related factors (CSMRF) has $97.6 \%$ effect by $R^{2}$ and $97.3 \%$ effect by adjusted $R^{2}$ on cost overrun followed by non-human resources related factors with $94.4 \%$ effect by $R^{2}$ and $93.8 \%$ by adjusted $R^{2}$ while the least is Information and communication related factors (ICTRF) having $75.7 \%$ and $73.0 \%$ respectively.

Table 2. Construct Coefficient of Determination.

\begin{tabular}{llll}
\hline Factors & $\boldsymbol{R}^{\mathbf{2}}$ & $\boldsymbol{R}^{\mathbf{2}}$ in \% & Adjusted $\boldsymbol{R}^{\mathbf{2}}$ \\
\hline CSMRF & 0.976 & 97.6 & 0.973 \\
DDRF & 0.865 & 86.5 & 0.850 \\
FMRF & 0.934 & 93.4 & 0.926 \\
HRRF & 0.884 & 88.4 & 0.871 \\
ICTRF & 0.757 & 75.7 & 0.730 \\
NHRF & 0.944 & 94.4 & 0.938 \\
\hline
\end{tabular}

Table 3. Construct Path Coefficient.

\begin{tabular}{|c|c|c|c|c|c|c|c|}
\hline & CSMRF & DDRF & FMRF & HRRF & ICTRF & NHRF & PMCARF \\
\hline CSMRF & & & & & & & \\
\hline DDRF & & & & & & & \\
\hline FMRF & & & & & & & \\
\hline HRRF & & 0.572 & 0.261 & & & & \\
\hline ICTRF & & & & & & & \\
\hline NHRF & & & & & & & \\
\hline PMCARF & 0.986 & 0.383 & 0.741 & & 0.908 & 0.971 & \\
\hline
\end{tabular}

Table 4. Construct Validity and Reliability.

\begin{tabular}{llllll}
\hline Factors & $\begin{array}{l}\text { Cronbach's Alpha } \\
\text { in \% }\end{array}$ & $\begin{array}{l}\text { Composite } \\
\text { Reliability }\end{array}$ & $\begin{array}{l}\text { Composite } \\
\text { Reliability in \% }\end{array}$ & $\begin{array}{l}\text { Average Variance } \\
\text { Extracted (AVE) }\end{array}$ \\
\hline CSMRF & 94.2 & 0.952 & 95.2 & 0.716 & \multicolumn{1}{c}{ rho_A } \\
DDRF & 97.3 & 0.979 & 97.9 & 0.904 & 0.949 \\
FMRF & 95.6 & 0.965 & 96.5 & 0.820 & 0.976 \\
HRRF & 94.8 & 0.960 & 96 & 0.829 & 0.959 \\
ICTRF & 93.7 & 0.959 & 95.9 & 0.887 & 0.957 \\
NHRF & 97.4 & 0.981 & 98.1 & 0.928 & 0.960 \\
PMCARF & 92.0 & 0.945 & 94.5 & 0.813 & 0.975 \\
\hline
\end{tabular}

\section{Summary and Conclusion}

In this study, the researchers assessed the management of cost overrun of projects in selected public tertiary institutions in Lafia metropolis using Partial Least Squares-Structural Equation Model (PLS-SEM). From PLS-SEM, the results shows that contractor's site management related factors has $97.6 \%$ effect on cost overrun, followed by non-human resource related factors with an effect of $94.4 \%$ on cost overrun. The least was information and communication technology related factors having $75.7 \%$ effect on cost overrun. From the findings, PLS-SEM is a model that evaluates a data as a collective entity. It reveals that the contractor's site management related factors (CSMRF) has $97.6 \%$ effect on cost overrun, followed by non-human resource related factors (NHRF) with $94.4 \%$ effect on overrun cost. Similarly, the least of the factors having effect on the cost overrun is the information and communication related factors (ICTRF) with a $75.7 \%$ effect on the cost overrun.

\section{Recommendation}

The study reveals that cost overrun can be reduced to the barest minimum if the clients (owners, government) take into consideration Contractor's site management related factors as well as Non-human resource related factors. This recommendation is made since both the inadequate monitoring and control of the price of materials to be used in the project are contained in the contractor's site management related factors and the non-human resource related factors that play vital role in the bidding state of each project. 


\section{References}

[1] Abam, A. O. \& Nzeako, G. C., (2017). A comparative study of Project Cost Overrun Management using Partial Least Squares- Structural Equation Modelling and Fuzzy Inference System. Department of Mathematics, Federal University Lafia, Unpublished Undergraduate Project.

[2] Ali, A. S. \& Kamaruzzaman, S. N., (2010), "Cost Performance for Building Construction Projects in Klang Valley", Journal of Building Performance, 1(1), 110-110.

[3] Azhar, N., Farooqui, R. U. \& Ahmed, S. M., (2008). Cost Overrun Factors in Construction Industry in Pakistan. Proceeding of First International Conference on Construction in Developing Countries (ICCIDE-1), Karachi, Pakistan, 4-5 August, 499-508, retrieved from http://www.neduet.edu.pk/Civil/ICCIDCconference\%20Proceedings/Papers/051.pdf.

[4] Bubshait, A. A. \& Al-Juwait, Y. A., (2002). Factors Contributing to Construction Costs in Saudi Arabia. Cost Engineering, 44(5), 30.

[5] Chin W. (2000). "Partial Least Squares for Researchers: An Overview and Presentation of Recent Advances Using the PLS Approach", http://disc-nt.cba.uh.edu/chin/indx.html.

[6] Choudhury, I., \& Phatak, O., (2004). Correlates of time overrun in commercial construction, ASC Proceeding of 4th Annual Conference, Brigham Young University- provo-Utah, April 8-10. Arabian international Journal of Project Management, 17(2), 101-106.

[7] Kagiri, D. (2005). Time and cost overruns in power projects: A case study of Kenya Electricity Generating Company. Unpublished MBA Project, University of Nairobi.

[8] Kaliba, C., Muya, M. \& Mumba, K., (2009). Cost Escalation and Schedule Delay in Road Construction Projects in Zambia, International Journal of Project Management, 5(27), 522-531.

[9] Koushki, P. A., Al - Rashid, K., \& Kartam, N., (2005). Delays and cost increases in the construction of private residential projects in Kuwait. Construction Management and Economics, 23(3), 285-294.

[10] Lee, J. K., (2008). Cost overrun and cause in Korean social overhead capital Projects: Roads, rails, airports and ports. $J$. Urban Planning. Dev., 2(134), 59-62.

[11] Love, P. E. D., Raymond, Y. C. T. \& David, J. E., (2005), Time-Cost Relations in Australia Building Construction Projects; ASCE Journal of Construction Engineering and Management, 2(131), 187-194.

[12] Mitzi (Maritza), P. T., (2008), Structural Equation Modeling Approach to Factors that Contribute to the impact MYMATHLAB has on Commitment and Integration of Technology, 65-71.

[13] Rational Choice Theory (2016). Retrieved from https://www.investopedia.com/terms/r/rational-choicetheory.asp.

[14] Rational Choice Theory (10 ${ }^{\text {th }}$ November, 2016). Retrieved from https://en.m.wikipedia.org/wiki/Rational_choice_theory.

[15] Rosenfield. Y., (2013), "Root Cause Analysis of Construction Cost Overruns," Journal of Construction Engineering and Management, 140.

[16] Shreenaath. A, Arunmozhi. S. \& Sivagamasundari, R., (2015), "Prediction of Construction Cost Overrun in Tamil Nadu- A Statistical Fuzzy Approach", International Journal of Engineering and Technical Research, 3(3), 267-275.

[17] Sriprasert, E., (2000). Assessment of Cost Control System: A Case Study of Thai Construction Organizations. Asian Institute of Technology, Bangkok. 